УДК $316.3 / 4$

DOI 10.18413/2712-746X-2020-45-1-42-50

\title{
ОТНОШЕНИЕ РАЗНЫХ ПОКОЛЕНИЙ РОССИЯН К ГОСУДАРСТВУ (СОЦИОЛОГИЧЕСКИЙ АСПЕКТ)
}

\section{THE ATTITUDE OF DIFFERENT GENERATIONS OF RUSSIANS TO THE STATE (SOCIOLOGICAL ASPECT)}

\author{
Л.Г. Лебедева \\ L.G. Lebedeva \\ Самарский государственный экономический университет, \\ Россия, 443090, г. Самара, ул. Советской Армии, 141 \\ Samara State University of Economics, \\ 141 Sovetskoi armii St, Samara, 443090, Russia \\ E-mail: ludleb@mail.ru
}

\begin{abstract}
Аннотация
Гармоничность отношений и взаимопонимание между разными поколениями предполагают достаточно высокую меру общности основных социальных ценностей, среди которых и государство, чьи интересы сограждане воспринимают как свои. Несмотря на многочисленные исследования взаимоотношений граждан и государства, эта проблема остается недостаточно изученной, в частности в поколенческом аспекте. Каково же реальное отношение россиян к государству? Интересы какого государства готовы отстаивать россияне разных поколений? Согласно данным проведенного автором социологического опроса готовность отстаивать интересы своего государства в большей мере признают представители младших возрастно-поколенческих групп («от 18 до 29 лет» и «от 30 до 44 лет»); в средней степени - представители группы «50 лет и старше» и в наименьшей степени - представители группы «от 45 до 49 лет». Наибольшую готовность отстаивать интересы своего государства проявляют те, кто считает, что России нужны «правовое государство, демократия» и «социальное государство, социальная защищённость». Наиболее последовательны в позиции «меня не касается» те, кто считает, что России нужны «либеральное государство, свобода рынка, свобода самовыражения». В последние годы в России практически застопорился рост экономики и благосостояния большинства населения, что обострило тягу масс к социальной защищённости. Таким образом, необходима более полная реализация на практике принципов социального государства. Соответственно, необходимо дальнейшее научное исследование основных направлений и механизмов эффективной реализации этих принципов.
\end{abstract}

\footnotetext{
Abstract

Harmony of relations and mutual understanding between different generations presupposes a fairly high degree of commonality of basic social values, including the state, whose interests are perceived by fellow citizens as their own. What is the real attitude of Russians to the state? Are Russians of different generations ready to protect the interests of their (existing) state? Despite numerous studies of the relationship between citizens and the state, in some aspects this problem remains insufficiently studied, in particular, in the generational aspect. With this in mind, the author of the article conducted a sociological study, which showed, in particular, the following. The willingness to defend the interests of their state is mostly recognized by representatives of younger age-generational groups ("18-29 years" and "30-44 years"); in the middle - by representatives of the group "50 years and older" and in the least - by representatives of the group "45-49 years". The greatest willingness to defend the interests of their state is shown by those who believe that Russia needs a "legal state, democracy" and a "social state, social security". And those who believe that Russia needs a "liberal state, freedom of the market, and freedom of expression" are the most consistent in the "it doesn't concern me" position. In recent years, the growth of the economy and
} 
the welfare of the majority of the population has almost stalled in Russia, which has exacerbated the desire of the masses for social security. The development of the state in modern Russia is associated with a set of tasks, including social justice and democracy, social security and ensuring the rights of citizens. These tasks can also be considered as principles of the social state. Citizens of different generations consider it necessary to implement these principles more fully in practice. Accordingly, further scientific research is needed on the main directions and mechanisms for effective implementation of the principles of the social state.

Ключевые слова: поколения, государство, социальные ценности, социальное государство, правовое государство, либеральное государство, справедливость.

Key words: generations, state, social values, social state, lawful state, liberal state, justice.

\section{Введение}

В последние десятилетия в связи с процессами глобализации и социальной трансформации в России произошли изменения в структуре общественных и личных ценностей россиян и межличностных отношений в духе либеральных частнособственнических ценностей, что явилось причиной разногласий и нарушений межпоколенных взаимосвязей (конфликта поколений). Важную роль в изменении структуры общественных и личных ценностей играет также сама по себе смена поколений. Так, именно смена поколений оказала большое влияние на распространение материалистических и постматериалистических ценностей, как это показано, в частности, в работе П. Абрамсона и Р. Инглхарта [Abramson, Inglehart, 1992] и в работе Инглхарта Р. и Вельцеля К. [2011] на примере ряда стран.

Между тем гармоничность отношений и взаимопонимание между разными поколениями предполагают достаточно высокую меру общности основных социальных ценностей. Речь, в частности, и о государстве (его типе) как одной из важнейших социальных ценностей. В одной из статей В.В. Путин подчеркнул необходимость общественного диалога, обсуждения того, какой вектор экономического и социального развития предпочесть, как можно улучшить нашу жизнь, сделать более справедливым общественное устройство [Путин, 2012а].

Проблема справедливости (наряду с проблемой демократии) находится в центре внимания многих исследователей и научных школ, в том числе в западных странах. При этом один из дискуссионных вопросов - является ли демократия требованием справедливости или инструментом ее реализации - имеет несколько вариантов ответа, из которых наиболее аргументирована точка зрения Лауры Валентини [Valentini, 2013]: демократию мы можем ценить как инструмент, справедливость мы должны ценить как таковую; теории справедливости (как самоценности) должны быть в центре внимания вместе с демократией (как инструментом). Иначе говоря, демократия важна и полезна не сама по себе, а как инструмент в определении и осуществлении того, что требует справедливость. Вряд ли нужно спорить с такой позицией.

В современной России положение о социальном государстве (по сути как институциональном инструменте реализации на практике демократии и социальной справедливости) возведено в один из конституционных принципов - в частности, в статье 7 Конституции Российской Федерации. Убедительно аргументированной представляется оценка, например, Н.И. Лапина [2018], который убежден в том, что формирование социального государства является способом успешной эволюции общества. Но приходится признать, что многое в реальном положении дел, в практике государства в России вызывает весьма критические замечания. Однако это относится и к другим социальным государствам, например, к странам Европейского Союза, где проблему основных устоев, легитимности и будущности социального государства (государства благосостояния) продолжают активно и разносторонне исследовать [Chung et al., 2018]. Так, в последние годы социальные исследования в западноевропейских странах показали, что «социальные инвестиции» гораздо бо- 
лее популярны в разных слоях общества по сравнению с «пассивными трансфертами» и «политикой оплаты труда» [Garritzmann et al., 2018]. Несомненно, что разработчики российской конституции учитывали имевшийся исторический опыт, в том числе, в странах Западной Европы. Этот опыт важно учитывать и сегодня в практике российского государства.

Актуальные аспекты проблемы социального государства отражены ранее в некоторых наших статьях [Лебедева, 2015a; 2015b; Лебедева, Орлова, 2018; 2019]. Данная статья по сути продолжает этот ряд исследований.

Каким же видится россиянам «более справедливое общественное устройство», желаемое и приемлемое для них государство, интересы которого воспринимаются как свои интересы? Соответственно, интересы какого государства (как справедливого) готовы отстаивать россияне разных поколений?

\section{Объекты и методы исследования}

Эмпирической базой при рассмотрении темы статьи явились, прежде всего, данные социологического опроса «"Отцы и дети": конфликт и сотрудничество, преемственность поколений 2018», организованного и проведённого под руководством Л.Г. Лебедевой в 2018 г. Анкетный опрос проводился в Самарской области. Выборочная совокупность была определена с учетом половозрастной и поселенческой структуры населения Самарской области. При расчётной выборочной совокупности респондентов, составившей 384 человека (предельная ошибка выборки 5 \%), было опрошено 438 респондентов, представляющих разные возрастно-поколенческие группы в возрасте от 18 лет и старше.

Важной особенностью социологического исследования «"Отцы и дети": конфликт и сотрудничество, преемственность поколений 2018» является выделение целевых возрастно-поколенческих групп респондентов, которые определялись с учётом социальноисторических условий, в которых та или иная возрастно-поколенческая группа вступала в свою взрослую жизнь (примерно в 16-18 лет). Для группы в возрасте 50 лет и старше (124 респондента) вхождение во взрослую жизнь пришлось на период до «перестройки» (до 1985 г.) - это молодёжь ещё советской поры. Группа в возрасте от 45 до 49 лет (97 респондентов), наоборот, входила во взрослую жизнь именно с 1985 по 1991 гг. - это молодёжь периода перестройки. Для группы в возрасте от 30 до 44 лет (105 респондентов) время взросления пришлось на период социальной трансформации российского общества (с 1991-1992 гг. примерно по 2007 г.) - это молодёжь первого постсоветского периода. Группа в возрасте 18-29 лет (112 респондентов) гражданское и личностное становление прошла в течение одиннадцати лет до проведения опроса (с 2007-2008 гг. по 2018 г.) - это сегодняшняя молодёжь.

\section{Материалы и результаты}

В какой степени готовы отстаивать интересы существующего в России государства сограждане разных возрастно-поколенческих групп, можно судить по результатам опроса, представленным в табл. 1 .

Основная масса ответов связана с двумя противоположными вариантами - «готов» отстаивать интересы своего государства и «меня не касается». Положительный ответ «готов» можно рассматривать как признак высокого уровня самоидентификации как гражданина российского государства. В наибольшей мере признают готовность отстаивать интересы своего государства представители младших возрастно-поколенческих групп - «от 18 до 29 лет» $(50,0$ \%) и «от 30 до 44 лет» (52,4 \%); в средней степени - представители группы «50 лет и старше» $(42,8 \%)$ и в наименьшей степени - представители группы «от 45 до 49 лет» $(38,1 \%)$.

Ответ «болен (стар)» выбрала четверть респондентов из возрастной группы «50 лет и старше» и одна двадцатая часть из возрастной группы «от 45 до 49 лет», что можно признать достаточно естественным (и уважительным) в силу зрелого возраста. А в младших возрастных группах («от 18 до 29 лет» и «от 30 до 44 лет») данный вариант ответа получил минимальную долю голосов (от 1,9 до 5,2 \%), что вполне естественно. 
Распределение ответов на вопрос «Вы готовы отстаивать интересы своего государства?» по возрастно-поколенческим группам, \% от выборочной совокупности респондентов Distribution of answers to the question "Are you ready to defend the interests of your state?" by age-generational groups, $\%$ of the sample of respondents

\begin{tabular}{|l|c|c|c|c|c|c|}
\hline \multirow{2}{*}{$\begin{array}{c}\text { Возрастно-поколенческие } \\
\text { группы }\end{array}$} & \multirow{2}{*}{$\begin{array}{c}\text { Выборочная } \\
\text { совокупность, } \\
n\end{array}$} & \multicolumn{4}{|c|}{ Ответы } & \multirow{2}{*}{ Всего } \\
\cline { 5 - 7 } & 112 & 50,0 & 2,7 & 36,6 & 10,7 & 100 \\
\hline От 18 до 29 лет & 105 & 52,4 & 1,9 & 32,4 & 13,3 & 100 \\
\hline От 30 до 44 лет & 97 & 38,1 & 5,2 & 46,4 & 10,3 & 100 \\
\hline От 45 до 49 лет & 124 & 42,8 & 26,6 & 26,6 & 4,0 & 100 \\
\hline 50 лет и старше & 438 & 45,9 & 9,8 & 34,9 & 9,4 & 100 \\
\hline Итого & & & & & & меня не касается \\
\hline
\end{tabular}

Около одной десятой части респондентов, в среднем по всей выборочной совокупности, выбрали ответ «другое», который можно рассматривать как уклончивый по существу ответ в значении «трудно сказать». При этом наименьшая доля таких ответов $(4,0 \%)$ отмечена в самой старшей возрастной группе («50 лет и старше»).

Отрицательный ответ «меня не касается» можно рассматривать как признак либо слабой меры самоидентификации, либо полного отсутствия гражданской самоидентификации-Этот ответ преимущественно выбрали представители группы «от 45 до 49 лет» $(46,4$ \%), то есть поколение периода перестройки, а наиболее редко его выбирали представители группы «50 лет и старше» $(26,6$ \%), то есть поколение доперестроечного периода. Данный социологический факт демонстрирует, как существенно и глубоко отразилась перестройка на общественном сознании респондентов возрастно-поколенческой группы «от 45 до 49 лет», этап взросления которых пришёлся именно на переломный период советской истории.

В сумме ответы «меня не касается» и «другое» преимущественно выбрали представители группы «от 45 до 49 лет» (56,9\%). Это можно рассматривать как один из признаков сравнительно низкого уровня гражданской самоидентификации именно у представителей данной группы.

В сумме ответы «меня не касается» и «другое» наиболее редко выбирали представители группы «50 лет и старше» $(30,6$ \%). Это можно рассматривать как один из признаков более высокого уровня гражданской самоидентификации именно у представителей старшей возрастнопоколенческой группы.

Но какое же по типу государство предпочитают россияне (табл. 2)?

Респонденты младшей (18-29 лет) возрастной группы и средних возрастных групп (30-44 лет и 45-49 лет) почти в одинаковой степени (примерно по две пятых части в каждой возрастной группе респондентов) высказались в пользу варианта «социальное государство, социальная защищённость». А респонденты старшей возрастной группы (50 лет и старше) на первое место выдвинули вариант «правовое государство, демократия» (также примерно две пятых части в этой группе респондентов).

В целом по всей выборочной совокупности две пятых части голосов (39,5 \%) отдано варианту «социальное государство, социальная защищённость»; одна треть голосов $(32,4 \%)$ - варианту «Правовое государство, демократия»; чуть менее одной пятой части голосов $(18,3 \%)$ - варианту «Либеральное государство, свобода рынка, свобода самовыражения». И около одной десятой части голосов $(9,8$ \%) по всей выборке отдано варианту «другое» (с которым может быть связано, например, «монархическое» или «социалистическое» государство). Интересы какого государства (типа государства) готовы или не готовы отстаивать россияне (табл. 3)? 
Таблица 2

Table 2

Распределение ответов на вопрос «Какое государство нужно России?» по возрастно-поколенческим группам, \% от выборочной совокупности респондентов

Distribution of answers to the question "What state does Russia need?"

by age-generational groups, $\%$ of the sample of respondents

\begin{tabular}{|c|c|c|c|c|c|c|}
\hline \multirow[b]{2}{*}{$\begin{array}{c}\text { Возрастно- } \\
\text { поколенческие } \\
\text { группы }\end{array}$} & \multirow[b]{2}{*}{$\begin{array}{c}\text { Выборочная } \\
\text { совокупность, } \\
\text { n }\end{array}$} & \multicolumn{4}{|c|}{ Ответы } & \multirow[b]{2}{*}{ Всего } \\
\hline & & $\begin{array}{c}\text { Правовое } \\
\text { государство, } \\
\text { демократия }\end{array}$ & $\begin{array}{c}\text { Социальное } \\
\text { государство, } \\
\text { социальная } \\
\text { защищённость }\end{array}$ & $\begin{array}{c}\text { Либеральное } \\
\text { государство, } \\
\text { свобода рынка, } \\
\text { свобода само- } \\
\text { выражения } \\
\end{array}$ & Другое & \\
\hline От 18 до 29 лет & 112 & 26,8 & 40,8 & 22,5 & 9,9 & 100 \\
\hline От 30 до 44 лет & 105 & 31,0 & 46,4 & 13,1 & 9,5 & 100 \\
\hline От 45 до 49 лет & 97 & 34,2 & 42,1 & 22,4 & 1,3 & 100 \\
\hline $\begin{array}{l}50 \text { лет } \\
\text { и старше }\end{array}$ & 124 & 37,7 & 29,4 & 24,7 & 8,2 & 100 \\
\hline Итого & 438 & 32,4 & 39,5 & 18,3 & 9,8 & 100 \\
\hline
\end{tabular}

Таблица 3

Table 3

Парное распределение ответов на вопросы «Какое государство нужно России?» и «Вы готовы отстаивать интересы своего государства?», \% от выборочной совокупности респондентов $(\mathrm{N}=438)$ Paired distribution of answers to the questions "What state does Russia need?" and "Are you ready to defend the interests of your state?", \% of the sample of respondents $(\mathrm{N}=438)$

\begin{tabular}{|l|c|c|c|c|c|}
\hline \multirow{2}{*}{\multicolumn{1}{|c|}{ Какое государство нужно России? }} & \multicolumn{4}{|c|}{ Вы готовы отстаивать интересы } & \multirow{2}{*}{ Всего } \\
\cline { 2 - 6 } & готов & $\begin{array}{c}\text { болен } \\
\text { (стар) }\end{array}$ & $\begin{array}{c}\text { меня } \\
\text { не касается }\end{array}$ & другое & \\
\hline Правовое государство, демократия & 19,4 & 3,0 & 5,9 & 4,1 & 32,4 \\
\hline $\begin{array}{l}\text { Социальное государство, } \\
\text { социальная защищённость }\end{array}$ & 19,2 & 4,5 & 13,2 & 2,5 & 39,5 \\
\hline $\begin{array}{l}\text { Либеральное государство, свобода рынка, } \\
\text { свобода самовыражения }\end{array}$ & 4,8 & 0,7 & 11,9 & 0,9 & 18,3 \\
\hline Другое & 2,5 & 1,6 & 3,9 & 1,8 & 9,8 \\
\hline Итого & 45,9 & 9,8 & 34,9 & 9,4 & 100 \\
\hline
\end{tabular}

Наибольшую готовность «отстаивать интересы своего государства» проявляют те, кто выбрал ответ «правовое государство, демократия» - таковых 19,4 \% по всей выборке, и те, кто выбрал ответ «социальное государство, социальная защищённость»- таковых 19,2 \% по всей выборке.

Наименьшую готовность «отстаивать интересы своего государства» проявляют те, кто выбрал ответ «либеральное государство, свобода рынка, свобода самовыражения» - таковых 4,8 \% по всей выборке, и те, кто выбрал ответ «другое» - таковых 2,5 \% по всей выборке.

В то же время позицию «меня не касается» в наибольшей мере отметили те, кто выбрал ответ «социальное государство, социальная защищённость» - таковых 13,2 \% по всей выборке, и те, кто выбрал ответ «либеральное государство, свобода рынка, свобода самовыражения» - таковых 11,9 \% по всей выборке. 
Позицию «меня не касается» в наименьшей мере отметили те, кто выбрал ответ «правовое государство, демократия» - таковых 5,9 \% по всей выборке, и те, кто выбрал ответ «другое» - таковых 3,9 \% по всей выборке.

Таким образом, наибольшую готовность «отстаивать интересы своего государства» проявляют те, кто выбрал ответы «правовое государство, демократия» и «социальное государство, социальная защищённость»; наиболее последовательны в позиции «меня не касается» те, кто выбрал ответ «либеральное государство, свобода рынка, свобода самовыражения».

\section{Обсуждение и выводы}

В общественном мнении россиян виднейшее место занимает социальная справедливость как ценность, как лозунг. Поэтому вполне естественно, что при ответах на вопросы о том, какое государство нужно России, и о готовности отстаивать интересы своего государства респонденты отдают предпочтение вариантам «правовое государство, демократия» и «социальное государство, социальная защищённость». В то же время, заметная часть респондентов отдаёт предпочтение варианту «либеральное государство, свобода рынка, свобода самовыражения». Таким образом подтверждаются результаты других социологических опросов, показывающие, что две трети россиян отвечают в консервативном ключе и треть - в либеральном [Бызов, 2016; Лебедева, Орлова, 2019]. Однако в разных возрастно-поколенческих группах те или иные тенденции (консервативные или либеральные) проявляются весьма неодинаково (см. табл. 2).

Поколенческий критерий «привития» и распространения важнейших социальных ценностей является универсальным. Так, на основе анализа британских социальных данных за 1985-2012 гг. М.Т. Грассо и её соавторы пришли к выводу, что в качестве наследия тэтчеризма явилось «долгосрочное формирование общественного мнения через политическую социализацию» [Grasso et al., 2019, p. 17]. Соответственно, воспитанное в обстановке тэтчеризма новое, молодое политическое поколение стало ещё в большей мере правым-авторитарным в сравнении со старшим (предыдущим) поколением. Таким образом, следует признать определённую динамику общественных ценностей в связи с социальноэкономическим и социально-политическим состоянием общества в тот или иной период.

В условиях экономических трудностей и кризиса в стране естественна актуализация проблем материального характера (в том числе, проблемы социального неравенства и социальной защищённости уязвимых слоёв населения). В более благополучные периоды подъёма, роста экономики и благосостояния населения естественно обострение внимания к проблемам демократии и свободы самовыражения.

В 2000-е годы в России произошёл заметный рост экономики и укрепились демократические основы политической системы. При этом проявила себя закономерность «опыт демократии в стране повышает ценности самовыражения» [Dahlum, Knutsen, 2016, p. 437]. Вместе с этим в последние годы практически застопорился рост экономики страны и благосостояния большинства населения, что обострило потребность граждан в социальной защищённости. Различные социологические исследования показывают массовый запрос россиян на содействие и поддержку со стороны государства; «только примерно шестая часть россиян заявляет, что им не нужно государственное содействие ни в какой форме» [Аникин, 2019, с. 352]

В.В. Путин отметил, что «эффективность социальной политики измеряется мнением людей - справедливо ли устроено общество, в котором мы живем» [Путин, $2012 b]$. В связи с этим он подчеркнул необходимость «завершить создание в России такой политической системы, такой структуры социальных гарантий и защиты граждан, такой модели экономики, которые вместе составят постоянно развивающийся и одновременно устойчивый, здоровый государственный организм» [Путин, 2012b].

Несомненно, что связь государства и населения (народа) взаимна. Государство действует для народа («за» народ) и народ действует для государства (и голосует «за» государство). Однако существуют проблемы как в отношении результатов деятельности государства, так и в отношении деятельности народа, его активных общественных сил. 
В частности, существует серьёзная общественная проблема - слабый «мобилизационный потенциал запроса на социальную справедливость» [Петухов, 2011, с. 22]. Для решения назревших социальных проблем недостаточно одного желания, необходимо ещё наличие определённой воли и практической энергии масс, сопряжение стремления к справедливости «с солидарностью, готовностью за эту самую справедливость бороться» [Петухов, 2011, с. 22].

Необходима и соответствующая политика со стороны государства - более последовательная и энергичная, в духе утверждения современного социального государства, за которое массы могли бы стоять горой. В том числе «речь о таких реформах, которые ведут к установлению общих и справедливых правил игры ("fairplay"), выравнивают возможности для разных членов общества» и «тем самым добавляют обществу социальной динамики» [Гимпельсон, Монусова, 2014, с. 217]. Пока же, как показывают приведённые выше социологические данные (см. табл. 1, 3), лишь около половины (и менее) респондентов заявляют о своей готовности отстаивать интересы своего (сегодняшнего) государства. Почему? Прежде всего потому, видимо, что результаты деятельности государства не вполне удовлетворительны для населения. Иначе говоря, российское государство ещё не стало в достаточной мере отвечающим высоким критериям именно «социального государства». Основная масса населения, особенно менее обеспеченные слои, ожидают от государства объективно необходимых «социальных инвестиций», прежде всего, в сферы образования и здравоохранения, в преодоление массовой бедности.

Как показывают научные данные и аргументы, в современных условиях в России, по оценке, например, Н.И. Лапина, «социальное государство предстает как фундаментальный институциональный принцип, определяющий перспективу российской государственности» [Лапин, 2018, с. 6]. Вновь актуализируется диагноз, сделанный в своё время Карлом Манхеймом: «Мир жаждет новой модели общественного переустройства»; при этом происходящие перемены «могут развиться в тип общества, который мог бы интегрировать в новую модель преимущества планирования и свободу демократического строя» [Манхейм, 1994, с. 446, 447]. Думается, что именно с современным социальным государством можно связывать подобную тенденцию и перспективу.

Несомненно, что различные аспекты развития и деятельности государства в России связаны так или иначе с комплексом задач, среди которых - социальная справедливость и демократия, социальная защищённость и обеспечение прав граждан, которые правомерно рассматривать и как общие принципы социального государства. В решении этих задач совпадают интересы россиян и положения Конституции Российской Федерации о государстве, прежде всего, как демократическом, правовом и социальном государстве, политика которого направлена на создание условий, обеспечивающих достойную жизнь и свободное развитие человека. Выработка путей и механизмов практической реализации государственными и общественными структурами всех этих задач предполагает и соответствующие социологические исследования.

На современном этапе основная масса населения, особенно менее обеспеченные слои, ожидают от государства объективно необходимых «социальных инвестиций», прежде всего, в сферы образования и здравоохранения, в преодоление массовой бедности. Таким образом, необходима, в конечном счёте, более полная реализация на практике принципов социального государства, соответственно, и выяснение путей, этапов и механизмов эффективной реализации этих принципов.

\section{Список литературы}

1. Аникин В.А., Лежнина Ю.П., Мареева С.В., Слободенюк Е.Д. 2019. Запросы россиян на содействие государства: социальное инвестирование или социальная поддержка? Мониторинг общественного мнения: Экономические и социальные перемены, 3: 345-366.

2. Бызов Л.Г. 2016. Ценностная трансформация российского общества на фоне социальнополитического кризиса и посткрымского синдрома. Общественные науки и современность, 6: 5-20.

3. Гимпельсон В.Е., Монусова Г.А. 2014. Восприятие неравенства и социальная мобильность. Экономический журнал Высшей школы экономики, 18 (2): 216-248. 
4. Горшков М.К. 2017. Российское общество в контексте новой реальности. Москва, Весь мир: $104 \mathrm{c.}$

5. Инглхарт Р., Вельцель К. 2011. Модернизация, культурные изменения и демократия: последовательность человеческого развития. Москва, Новое издательство: 464 с.

6. Лапин Н.И. 2018. Формирование социального государства - способ успешной эволюции общества. Социологические исследования, 8: 3-11. DOI: 10.31857/S013216250000758-6

7. Лебедева Л.Г. 2015а. Преемственность поколений в дискурсе менеджмента проблем социального государства в России. Вестник Самарского муниципального института управления, 3 : $132-138$.

8. Лебедева Л.Г. 2015b. Социальное государство как императив гармоничной преемственности поколений в России. Вестник Самарского муниципального института управления, 2: 147-157.

9. Лебедева Л.Г., Орлова Л.В. 2018. Социальное государство в социологическом зеркале преемственной связи российских поколений. Вестник Самарского муниципального института управления, 4: 133-139.

10. Лебедева Л.Г., Орлова Л.В. 2019. Социальный выбор современных российских поколений (социологический аспект). Социально-экономические явления и процессы, 14(105): 512. DOI: $10.20310 / 1819-8813-2019-14-105-5-12$

11. Манхейм К. 1994. Диагноз нашего времени. М., Юрист: 700 с.

12. Петухов В.В. 2011. Ценностная палитра современного российского общества: «идеологическая каша» или поиск новых смыслов? Мониторинг общественного мнения: экономические и социальные перемены, 1: 6-23.

13. Путин В.В. 2012а. Россия сосредоточивается - вызовы, на которые мы должны ответить. URL: http://www.izvestia.ru/news/511884 (дата обращения 22.10.2019).

14. Путин В.В. 2012b. Строительство справедливости. Социальная политика для России. URL: http://www.rg.ru/2012/02/13/putin-statya.html (дата обращения 22.10.2019).

15. Abramson P. \& Ingelhart R. 1992. Generational Replacement and Value Change in Eight West European Societies. British Journal of Political Science, 22. DOI: 10.1017 /S0007123400006335.

16. Chung H., Taylor Gooby P., Leruth B. 2018. Political legitimacy and welfare state futures: Introduction. Social Policy Administration, 52: 835-846. DOI: 10.1111/spol.12400

17. Dahlum S. \& Knutsen C. 2017. Democracy by demand? Reinvestigating the effect of selfexpression values on political regime type. British Journal of Political Science, 47(2): 437-461. DOI: $10.1017 / \mathrm{S} 0007123412000294$

18. Garritzmann Ju. \& Busemeyer M. \& Neimanns E. 2018. Public demand for social investment: new supporting coalitions for welfare state reform in Western Europe? Journal of European Public Policy, 25: 844-861. DOI: 10.1080/13501763.2017.1401107.

19. Grasso M., Farrall S., Gray E., Hay C., \& Jennings W. 2019. Thatcher's Children, Blair's Babies, Political Socialization and Trickle-down Value Change: An Age, Period and Cohort Analysis. British Journal of Political Science, 49 (1): 17-36. DOI: 10.1017 /S0007123416000375

20. Valentini L. 2013. Justice, Disagreement and Democracy. British Journal of Political Science, 43 (1): 177-199. DOI: 10.1017/S0007123412000294

\section{References}

1. Anikin V.A., Lezhnina Y.P., Mareeva S.V., Slobodenyuk E.D. 2019. Zaprosy rossijan na sodejstvie gosudarstva: social'noe investirovanie ili social'naja podderzhka? [Russian Public Demand for State Assistance: Social Investment or Social Support?]. Monitoring obshhestvennogo mnenija: jekonomicheskie i social'nye peremeny, 3: 345-366.

2. Byzov L.G. 2016. Tsennostnaya transformatsiya rossijskogo obshchestva na fone sotsial'nopoliticheskogo krizisa i postkrymskogo sindroma [Valuable transformation of the Russian society against the background of socio-political crisis and the post-Crimean syndrome]. Obshchestvennye nauki i sovremennost', 6: 5-20.

3. Gimpel'son V.E., Monusova G.A. 2014. Vosprijatie neravenstva i social'naja mobil'nost' [Perceptions of inequality and social mobility]. Jekonomicheskij zhurnal Vysshej shkoly jekonomiki, 18 (2): $216-248$.

4. Gorshkov M.K. 2017. Rossiyskoye obshchestvo v kontekste novoy real'nosti [Russian society in the context of a new reality]. Moskva. Ves' mir: 104 p. 
5. Inglhart R., Vel'cel' K. 2011. Modernizacija, kul'turnye izmenenija i demokratija: posledovatel'nost' chelovecheskogo razvitija [Modernization, cultural change and democracy: the sequence of human development]. Moskva, Novoe izdatel'stvo: $464 \mathrm{p}$.

6. Lapin N.I. 2018. Formirovanie social'nogo gosudarstva - sposob uspeshnoj jevoljucii obshhestvab [Formation of a social state as a way of successful evolution of society]. Sociologicheskie issledovanija, 8: 3-11. DOI: 10.31857/S013216250000758-6

7. Lebedeva L.G. 2015a. Preemstvennost' pokolenij v diskurse menedzhmenta problem sotsial'nogo gosudarstva $\mathrm{v}$ Rossii [Continuity of generations in a discourse of management of problems of the social state in Russia]. Vestnik Samarskogo munitsipal'nogo instituta upravleniya, 3: 132-138.

8. Lebedeva L.G. 2015b. Social'noe gosudarstvo kak imperativ garmonichnoj preemstvennosti pokolenij v Rossii [Social state as an imperative of harmonious succession of generations in Russia]. Vestnik Samarskogo municipal'nogo instituta upravlenija, 2: 147-157.

9. Lebedeva L.G., Orlova L.V. 2018. Social'noe gosudarstvo v sociologicheskom zerkale preemstvennoj svjazi rossijskih pokolenij [The social state in the sociological mirror of the continuity of Russian generations]. Vestnik Samarskogo municipal'nogo instituta upravlenija, 4: 133-139.

10. Lebedeva L.G., Orlova L.V. 2019. Social'nyj vybor sovremennyh rossijskih pokolenij (sociologicheskij aspekt) [Social choice of modern Russian generations (sociological aspect)]. Social'nojekonomicheskie javlenija i process, 14 (105): 5-12. DOI: 10.20310/1819-8813-2019-14-105-5-12

11. Manheim K. 1994. Diagnoz nashego vremeni [The diagnosis of our time]. M., Jurist: 700 p.

12. Petyhov V.V. 2011. Cennostnaja palitra sovremennogo rossijskogo obshhestva: «ideologicheskaja kasha» ili poisk novyh smyslov? [Valuable palette of modern Russian society: "ideological porridge" or search of new meanings?]. Monitoring obshhestvennogo mnenija: jekonomicheskie i social'nye peremeny, 1: 6-23.

13. Putin V.V. 2012a. Rossija sosredotochivaetsja - vyzovy, na kotorye my dolzhny otvetit' [Russia concentrates - calls which we have to answer]. Available at: http://www .izvestia.ru/news/511884 (accessed 22.10.2019).

14. Putin V.V. 2012b. Stroitel'stvo spravedlivosti. Social'naja politika dlja Rossii [Justice construction. Social policy for Russia]. Available at: http://www.rg.ru/2012/02/13/putin-statya.html (accessed 22.10.2019).

15. Abramson Paul \& Ingelhart R. 1992. Generational Replacement and Value Change in Eight West European Societies. British Journal of Political Science, $22(2)$, 183228. DOI: $10.1017 / \mathrm{S} 0007123400006335$.

16. Chung H., Taylor Gooby P., Leruth B. 2018. Political legitimacy and welfare state futures: Introduction. Social Policy Administration, 52: 835-846. DOI: 10.1111/spol.12400

17. Dahlum S. \& Knutsen C. 2017. Democracy by demand? Reinvestigating the effect of selfexpression values on political regime type. British Journal of Political Science, 47(2): 437-461. DOI: $10.1017 / \mathrm{S} 0007123412000294$

18. Garritzmann Ju. \& Busemeyer M. \& Neimanns E. 2018. Public demand for social investment: new supporting coalitions for welfare state reform in Western Europe? Journal of European Public Policy, 25(6): 844-861. DOI: 10.1080/13501763.2017.1401107.

19. Grasso M., Farrall S., Gray E., Hay C., \& Jennings W. 2019. Thatcher's Children, Blair's Babies, Political Socialization and Trickle-down Value Change: An Age, Period and Cohort Analysis. British Journal of Political Science, 49 (1): 17-36. DOI: 10.1017 /S0007123416000375

20. Valentini L. 2013. Justice, Disagreement and Democracy. British Journal of Political Science, 43 (1): 177-199. DOI: 10.1017/S0007123412000294

\section{Ссылка для цитирования статьи For citation}

Лебедева Л.Г. 2020. Отношение разных поколений россиян к государству (социологический аспект). NOMOTHETIKA: Философия. Социология. Право. 45 (1): 42-50.

DOI 10.18413/2712-746X-2020-45-1-42-50

Lebedeva L.G. 2020. The attitude of different generations of russians to the state (sociological aspect). NOMOTHETIKA: Philosophy. Sociology. Law series. 45 (1): $42-50$ (in Russian).

DOI 10.18413/2712-746X-2020-45-1-42-50 